\title{
International Geoscience Programme (IGCP) Project Proposal Form
}

Important: Please fill in the boxes below using a computer and following closely the instructions provided at the bottom of this form, print a copy, sign it, and send it to:

\author{
IGCP Secretariat \\ Division of Ecological and Earth Sciences \\ UNESCO \\ 1 rue Miollis \\ F-75732 Paris Cedex 15 \\ France
}

Another copy should be sent as an attachment via e-mail to:igcp@unesco.org

Proposals must reach Paris by October 15th in order to be considered for funding for the following year.

1. Indicate the topic into which the project falls:

(i) Topics of particular interest to IGCP

1.1 Geoscience of the Water Cycle

1.2 Geohazards

1.3 Earth Resources

1.4 Global Change and Life Evolution

1.5 The Deep Earth

(ii) Annually defined topics

(iii) Other relevant topics in basiclapplied geoscience

If this is a Young Scientist Project proposal please tick here

\section{Short title of the project:}

3. Full title of the project:

4. Proposed by:

5. Scale of the project:

$$
\begin{aligned}
& \text { - sub-continental/regional } \\
& \text { - continental } \\
& \text { - inter-continental } \\
& \text { - global }
\end{aligned}
$$

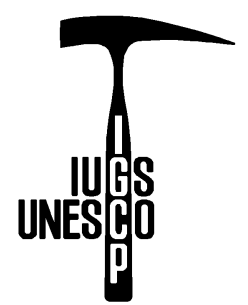




\section{Full description of the project (sections 8.1 through 8.10)}

8.1 Aims and background:

8.2 Significance:

8.3. Present state of activities in the field of the proposed project:

8.4 Workplan (items by year):

\begin{tabular}{l}
\hline \\
8.5 Results expected: \\
a) in basic sciences \\
b) in applied sciences and technology \\
c) in respect of benefit to society \\
\hline
\end{tabular}

8.6 Participation:

a) what countries or institutions (or individuals) have already agreed to co-operate?

b) what countries and institutions are likely to participate in the project?

8.7 Location of major field activities:

8.8 Location of major laboratory research (assured co-operation of laboratories):

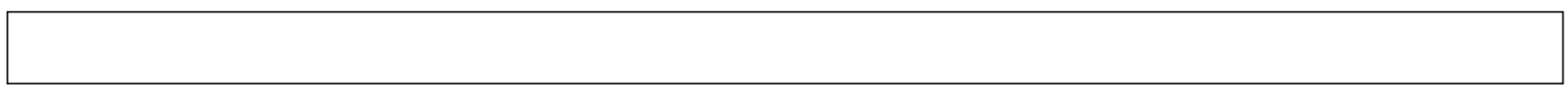

8.9 Budget

8.10 Curriculum Vitae of proposer(s)

\section{Attach letter of endorsement of IGCP/IUGS National Committee}

It is understood that the project leader will be responsible for the submission of annual progress reports, financial statement(s) on the use of IGCP funds, as well as bibliographic data of all publications dealing with the results or activities of the project, all announcements of international public activities which may be connected with the project, such as conferences, field trips, workshops and courses, and a detailed final report when the project has been finished.

It is further understood that the results of the project will be published, preferably in international peer-reviewed publications. One copy of each publication or circulated document will be supplied to the IGCP Secretariat.

It is further understood that each publication resulting from the project has to carry, at a prominent place, a statement that it is a contribution to the International Geoscience Programme, specifying the number of the project.

In books resulting from the project, the title page and, when technically possible, the cover should also carry the official logo of the IGCP.

Date: 


\section{Guidelines for filling in the Proposal Form}

Completion of the proposal form should conform to the following instructions. For more general issues, please refer to the Call for IGCP Project Proposals.

1. Please mark on the proposal form the relevant topic(s). For the Annually defined topics -if any- refer to the annual Call for IGCP Project Proposals.

2. The short title of the project should be as brief as possible but still identify its main objective.

3. The full title should be limited to a maximum of around fifteen words.

4. Academic titles and names of the proposer(s) should be inserted. Provide also full mailing address(es), telephone, fax numbers, and e-mail address(es). The first listed name will be the focal point for future correspondence.

5. The scale of the project must be indicated among the choice given.

6. Provide a maximum 600 words-long, self-contained summary of the project, including its societal benefits. It should be written in plain English and for the non-specialist using a minimum of terminology unique to the area of study.

7. The estimated duration of the project should be stated. Maximum life-time of an IGCP project can be five years.

8.1 Describe the aims and rationale of the proposal. Include information on work already undertaken by the proposers that is relevant to the proposal. Maximum length: 2,000 words, including bibliography.

8.2 Describe why the project is significant (scientific advancement, international cooperation, knowledge transfer, technological advancement, etc.) and why support through IGCP funding is crucial to its success. Maximum length: 1,500 words.

8.3 Describe the present state of activities in the field of the proposed project. Include the names of relevant institutions and persons in charge. This should be precisely stated since it reflects the proposer's awareness of the general state of the proposed reasearch field. Maximum length: 2,000 words.

8.4 The work schedule should be prepared bearing in mind that, as a rule, projects will be accepted for a duration of five years maximum. The work schedule should include field and labora- tory work, meetings, field trips, conferences, etc. Maximum length: 1,500 words.

8.5 Results expected should be specified as precisely as possible in respect of theoretical and applied science (including general applications where these are foreseen), as well as anticipated societal benefits. Outcomes should include both those expected at the end of the project as well as those to be achieved at the end of each year for which funding is requested. Meetings and conferences are not considered as results. Maximum length: 2,000 words.

8.6 Provide a list of contributors to the project and the areas to which they will contribute.

a) "agreed to cooperate" implies a formal commitment supported by written confirmation. Names and addresses should be listed.

b) "likely to participate" invites the proposer(s) to estimate the range of participation of those who have shown interest in the project but whose written commitment is still awaited.

Applicants should note that an important aim of this program is to encourage involvement of scientists from the developing countries.

8.7 State the principal locations of any planned field investigations.

8.8 State names and locations of laboratories that have agreed to conduct laboratory work.

8.9 Outline how the IGCP funds will be spent over the proposed duration of the project. List other potential sources of funds and how IGCP funds may help in leveraging funds from other organizations. Provide a realistic estimate of the total cost of the project, itemizing expenditures such as fieldwork expenses, laboratory costs, meetings, etc.

$8.10 \mathrm{CVs}$ of proposed leader(s) should be limited to three pages and include key publications (international peer-reviewed publications only), relevant scientific experience, any previous involvement in IGCP and/or other international research cooperation programs, including the organization of international meetings.

9. Attach letter of endorsement of the main proposer's IGCP National Committees or IUGS National Committees.

\section{The Chronologers' Quest}

\section{The Search for the Age of the Earth}

\section{Patrick Wyse Jackson}

The debate over the age of the Earth has been on-going for over 2000 years, and has pitted physicists and astronomers against biologists; religious philosophers against geologists. The Chronologers' Quest tells the fascinating story of our attempts to determine the age of the Earth.

This book investigates the many novel methods used in the search for the Earth's age, from James Ussher and John Lightfoot examining biblical chronologies, Comte de Buffon and Lord Kelvin determining the length of time for the cooling of the Earth, to the more recent investigations of Arthur Holmes and Clair Patterson into radiometric dating of rocks and meteorites.

The Chronologers' Quest is a readable account of the measurement of geological time. It will be of great interest to a wide range of readers, from those with little scientific background, to students and scientists in a wide range of the earth sciences.

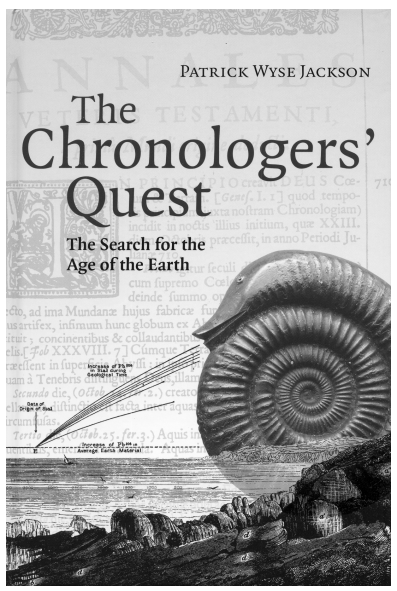

Cambridge University Press www.cambridge.org 2006

USD $30.00 / £ 19.99$ ISBN 10 0-521-81332-8 